\title{
Superb Microvascular Imaging (SMI) - Doppler Technique in the Evaluation of the Endometrial Polyp and Submucosal Myoma in Postmenopausal Overweight Women
}

\author{
[Dỉrem ŞENYUVA ${ }^{\mathrm{a}},{ }^{\circledR}$ Şirin KÜÇÜK ${ }^{\mathrm{b}},{ }^{\circledR}$ Senem ŞENTÜRK ${ }^{\mathrm{c}}$,

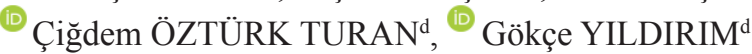 \\ ${ }^{a}$ Clinic of Obstetrics and Gynecology, Uşak Training and Research Hospital, Uşak, TURKEY \\ ${ }^{b}$ Department of Pathology, Ușak University Faculty of Medicine, Ușak, TURKEY \\ 'Department of Radiology, Uşak University Faculty of Medicine, Ușak, TURKEY \\ ${ }^{\mathrm{d}}$ Clinic of Radiology, Uşak Training and Research Hospital, Uşak, TURKEY
}

\begin{abstract}
Objective: The aim of this study was to evaluate postmenopausal endometrial polyp (EP) and submucosal myoma (SMM) vascularity with two-dimensional transabdominal ultrasonography (TAUSG) - Superb Microvascular Imaging (SMI) Doppler and to correlate with histopathological findings. Material and Methods: 11 cases with postmenopausal bleeding and increased endometrial thickness were included in the study. Endometrial vascularity was assessed by TAUSG with conventional and SMI Doppler and Vascularity Index (VI) was calculated. The number of vessels and histopathological findings were correlated. Results: VI was $0.2(0-2) \pm 0.6$ in conventional colour Doppler, $0.2(0-2) \pm 0.6$ in power Doppler, $2.5(0-8) \pm 3$ in colour-SMI and $3.8(0-12) \pm 4.2$ in monochrome SMI. VI was found to be significantly lower in the traditional Doppler group than the SMI Doppler group $(\mathrm{p}=0.018)$. Pathological examination revealed EP in 8 patients $(72.7 \%)$, SMM in three patients (27.2\%).In the comparison of the number of vessels observed in the VI and pathological sections, the rate of capturing the vessels was significantly lower in the traditional, colour and monochrome SMI Doppler groups $(p=0.03, p=0.07, p=0.016)$. In the correlation between Body Mass Index and VI, VIs were found to be low in all cases and there were no statistically significant differences between the traditional, colour and monochrome SMI Doppler measurements and weight measurements $(p=0.2273, p=0.848, p=0.999)$. Conclusion: We found that TAUSG-SMI Doppler may be not enough for imaging of lesion vascularity. Uterus is a deeply located organ so transabdominal route may be not be a proper option in overweight women.
\end{abstract}

Keywords: Doppler; endometrium; microvessel; pathology; post-menopause; ultrasonography

Ultrasonography (USG) is an important diagnostic method in the practice of gynaecology. The evaluation of endometrial morphology with Doppler sonography in addition to the two-dimensional USG is important for the diagnosis of endometrial lesions. ${ }^{1}$ While the conventional colour Doppler is insufficient to identify vessels smaller than $1 \mathrm{~mm}$ and flows lower than $3-5 \mathrm{~cm} / \mathrm{sec}$, power Doppler is useful in low flow imaging. ${ }^{2}$

Superb Micro Vascular Imaging (SMI) is a new Doppler technique. It displays low blood flow in vessels with small diameters by eliminating the tissue movement-related artefact compared to the conven- tional colour and power Doppler. The wall filter existing in conventional Doppler eliminates the interference and tissue motion artefact, however reduces the capture of low velocity flows. ${ }^{3}$

Transvaginal USG (TVUSG) is typically used in the evaluation of the endometrial cavity. However, analysis with transabdominal USG (TAUSG) may be required in cases of large fibroids, pathologies in which the uterus has a large size, virgo, vaginismus, vaginal stenosis, etc. ${ }^{4}$

Post-menopausal endometrium is seen as an atrophic, thin echogenic line in two-dimensional USG. ${ }^{5}$ Endometrial polyp (EP) and submucosal

\section{Correspondence: İrem ŞENYUVA \\ Clinic of Obstetrics and Gynecology, Uşak Training and Research Hospital, Uşak, TURKEY \\ E-mail: iremsenyuva@yahoo.com \\ Peer review under responsibility of Journal of Clinical Obstetrics \& Gynecology.


myoma (SMM) can lead to bleeding in the postmenopausal period, and it is important to evaluate endometrial morphology and vascularity in diagnosis. $^{4,6}$

In this study, endometrial vascularity has been evaluated with two-dimensional transabdominal SMI-Doppler in the diagnosis of post-menopausal EP and SMM, and the histopathological correlation of the obtained results has been assessed.

\section{CASE REPORT}

A total of 11 women who applied to Uşak University Faculty of Medicine Training and Research Hospital Gynaecology and Obstetrics Outpatient Clinic between March 2018 and June 2018 due to postmenopausal bleeding were included in the study. These patients were diagnosed with focal or diffuse endometrial thickening in TAUSG and were performed dilatation and curettage (D\&C). All of patients did not receive hormone replacement therapy.

This study was approved by Uşak University Medical Faculty Ethics Committee with 75-07-03 number. Informed consent was obtained all patients. The mean age of the patients was $55.18 \pm 6.03$ (range 46-63), and their mean body mass index (BMI) was $29.71 \pm 3.9 \mathrm{~kg} / \mathrm{m}^{2}$ range $(25.8-37.3)$. The cases were considered overweight if $\mathrm{BMI}=25.0-29.9 \mathrm{~kg} / \mathrm{m}^{2}$ and obese if BMI $\geq 30 \mathrm{~kg} / \mathrm{m}^{2}$ according to Turkish Endocrinology and Metabolism Association Obesity Diagnosis and Treatment Guidelines.?

USG examination has been performed with Toshiba Aplio 500 ultrasonography (Toshiba, Aplio 500, Tokyo, Japan) device on which the SMI Doppler version was installed, using a 1-6 MHz convex probe, in the Radiology Policlinic Ultrasonography Unit. Video images of 5 to 12 seconds length, obtained by scanning the lesion with TAUSG have been archived.

The endometrial thickness has been measured from the thickest vertical section including two endomyometrial lines in the middle in the sagittal plane. Endometrial morphology and vascular pattern have been defined according to the International Endometrial Tumour Analysis (IETA) group criteria. ${ }^{4}$ Echogenicity, intracavitary fluid, midline and endomyometrial junction have been analysed in the mor- phological evaluation; single dominant vessel \pm branching, multiple vessels of focal origin have been analysed in the vascular pattern, and multifocal origin, complex vessels and circular flows have been analysed in the endo-myometrial zone.

Endometrial vascularity has been defined in accordance with the International Ovarial Tumour Analysis (IOTA) group criteria. ${ }^{4}$ Accordingly, the endometrial blood flow is divided into 4 categories: Grade 1: No filling with colour, Grade 2: One or more punctate colour coding in the endometrium, Grade 3: One linear colour coding or multiple $(>5)$ punctate colour coding in the endometrium, Grade 4: Multiple linear colour coding in the endometrium. Vascularity index (VI) has been calculated by giving 1 point to punctate vessels and 2 points to linear vessels.

The vascularization rating has been performed separately with colour Doppler, power Doppler, colour SMI (c-SMI) and monochrome SMI (mcSMI) USG methods. The recorded video images have been evaluated by three radiologists and rated by their consensus decision.

In order to identify the endometrial vessels in pathological diagnosis, the sections have been primarily scanned at small magnification (x40) and four areas that were abound in vessels have been identified, then the micro-vessels in these four areas have been counted at $\mathrm{x} 200$ magnification and the mean vascular density (MVD) has been calculated. All evaluations have been carried out by a single pathologist. ${ }^{8}$ The mean vascular density of endometrial lesions were detected $7.9(5-11.5) \pm 2.4$ in histopathologic specimens.

Histopathological results have been compared with the endometrial vascularity results obtained by transabdominal conventional Doppler and SMI Doppler methods.

The mean endometrial thickness was 12.3 (622) \pm 5.0 . Endometrial echogenicity was hyperechogenic in all cases, and echogenicity was uniform in $4(36.3 \%)$ cases and non-uniform in $7(63.6 \%)$ cases.

According to the result of the pathological examination, 8 (72.7\%) patients were diagnosed with EP and $3(27.2 \%)$ patients were diagnosed with SMM. 


\begin{tabular}{|lllll|}
\hline \multicolumn{5}{c}{ TABLE 1: Morphology and vascular patern of endometrium. } \\
\hline & Pathology & Echogenicity & Vascular pattern & Endo-myometrial junction \\
\hline 1 & SMM & Hyperechogenic-non uniform & Avascular & Regular \\
\hline 3 & SMM & Hyperechogenic-non uniform & Avascular & Regular \\
\hline 4 & SMM & Hyperechogenic-uniform & Scattered, punctate & Regular \\
\hline 5 & EP & Hyperechogenic-non uniform & Scattered, punctate & Regular \\
\hline 6 & EP & Hyperechogenic-uniform & Avascular & Regular \\
\hline 7 & EP & Hyperechogenic-non uniform & Single dominant vessel & Regular \\
\hline 8 & EP & Hyperechogenic-non uniform & Multifocal vessel & Regular \\
\hline 10 & EP & Hyperechogenic-non uniform & Avascular & Regular \\
\hline 11 & EP & Hyperechogenic-non uniform & Avascular & Regular \\
\hline
\end{tabular}

SMM: Submucosal myoma, EP: Endometrial polyp.

Two of the three cases that were diagnosed with SMM in the TAUSG-SMI vascular Doppler pattern showed avascular pattern $(66.6 \%)$, while one showed dispersed punctate vessel (33.3\%). The vascular patterns observed in 8 cases with EP were single dominant vessel $(25 \%, \mathrm{n} / 8)$, dispersed punctate vessel $(25 \%, \mathrm{n} / 8)$, multifocal vessel $(12.5 \%, \mathrm{n} / 8)$ and avascular pattern $(37.5 \%, \mathrm{n} / 8)$.

Endometrial morphology and vascular pattern results are given in Table 1, while VI and MVD in histopathological examination are given in Table 2.

Comparison of the Doppler methods and the MVD observed in pathological cross-sections are given in Table 3.

Conventional and SMI Doppler images of EP are shown in Figure 1 while histopathological results of EP and SMM are shown in Figure 2 and Figure 3.

\section{DISCUSSION}

In this study, EP and SMM in aetiology of patients with postmenopausal bleeding with increased endometrial thickness have been identified. It has been found that SMI Doppler is superior in detecting vascularity in these lesions compared to conventional Doppler in TAUSG, however this technique failed to detect vascularity of endometrial lesions when compared with histopathological examinations.

The uterus is a deeply located organ in the pelvis, and its size is reduced in postmenopausal cases. Considering that the BMIs of the patients were

\begin{tabular}{|ccccccc|}
\hline \multicolumn{6}{|c|}{ TABLE 2: Vascularity index and mean vascular density. } \\
\hline & & C-VI & P-VI & c-SMI VI & mc-SMI VI & MVD \\
1 & SMM & 0 & 0 & 0 & 0 & 5.5 \\
2 & SMM & 0 & 0 & 0 & 0 & 6.5 \\
3 & SMM & 0 & 0 & 8 & 8 & 5 \\
4 & EP & 0 & 0 & 5 & 5 & 11 \\
\hline 5 & EP & 0 & 0 & 0 & 0 & 11.5 \\
6 & EP & 0 & 0 & 2 & 2 & 7 \\
7 & EP & 0 & 0 & 7 & 9 & 7 \\
8 & EP & 0 & 0 & 0 & 0 & 8.75 \\
9 & EP & 0 & 0 & 0 & 0 & 5 \\
10 & EP & 2 & 2 & 2 & 2 & 11 \\
11 & EP & 0 & 0 & 4 & 4 & 8.75 \\
\hline
\end{tabular}

SMM: Submucosal myoma, EP: Endometrial polyp, SMI: Superb microvascular ima-ging, C-VI: Color vascularity index, P-VI: Power vascularity index, c-SMI VI: Color SMI vascularity index, mc-SMI VI: Monochrome SMI vascularity index, MVD: Mean vascular density.

\begin{tabular}{|c|c|c|}
\hline Doppler & $\begin{array}{c}\text { VI } \\
\text { Mean (max-min } \pm S D)\end{array}$ & $\begin{array}{c}\text { MVD } \\
\text { Mean (max-min } \pm S D)\end{array}$ \\
\hline c-SMI & $2.5(0-8) \pm 3$ & \\
\hline mc-SMI & $3.8(0-12) \pm 4.2$ & $7.9(5-11.5) \pm 2.4$ \\
\hline Color-Doppler & $0.2(0-2) \pm 0.6$ & \\
\hline Power-Doppler & $0.2(0-2) \pm 0.6$ & \\
\hline
\end{tabular}

VI: Vascularity index, SMI: Superb microvascular imaging. c-SMI: Color SMI, mc-SMI: Monochrome SMI, MVD: Mean vascular density.

in the overweight category, it is understood that in conventional SMD Doppler techniques such as SMI Doppler, it gets difficult to detect vascularity in endometrial lesions due to the insufficiency of the 


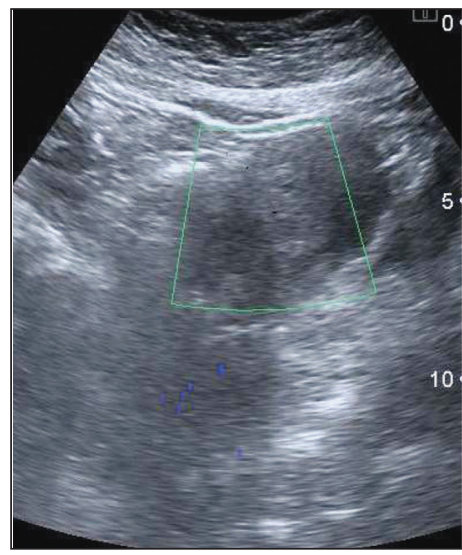

A. Traditional Doppler

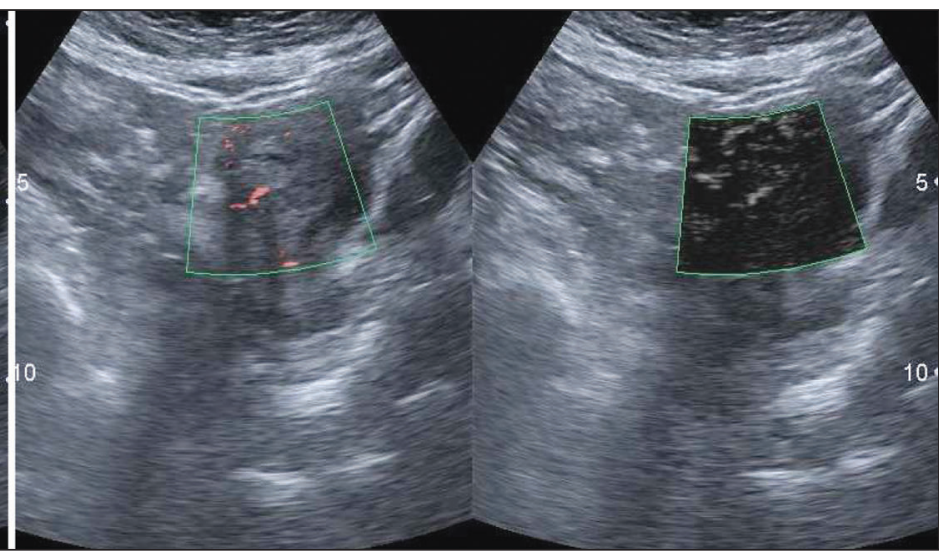

B. Color-SMI

C. Monochrome-SMI

FIGURE 1: Doppler imaging of endometrial polyp vascularity. SMI: Superb microvascular imaging.

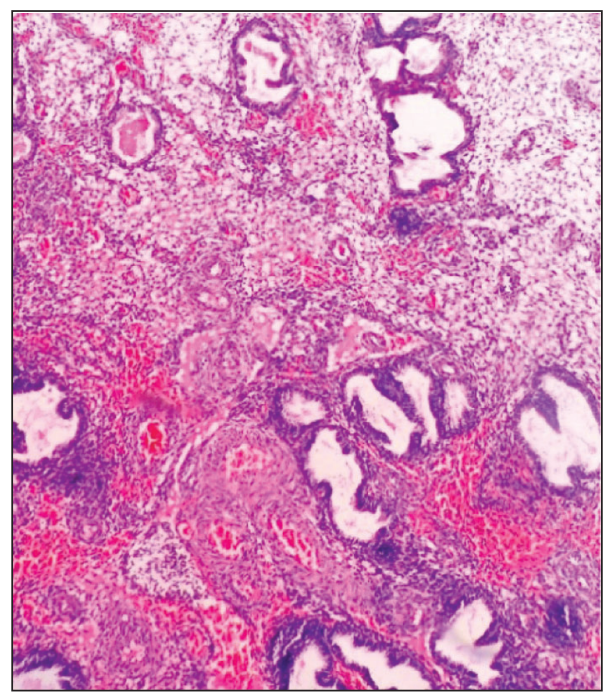

FIGURE 2: Endometrial polyp.

Endometrial polyp specimen consisted of single layer surface epithelium, edematous and dens thicker wall stromal vessels, single layer and stratifiye epithelium floored cystic-dilate gland structure (H\&E X20).

Doppler echos for tissue penetration. The endometrium thicknesses of our cases were 6-22 mm, and the lesion sizes were small. We believe that the small size of the lesions and thus the vascular structures also makes it difficult to detect vascularity by TAUSG Doppler methods.

Even though today's sonographic image quality is increased with techniques such as high frequency transducers and harmonic imaging, artefacts are still observed in ultrasound images. ${ }^{9}$ Artefacts are common conditions in two-dimensional USG and
Doppler methods. They originate from reasons such as the physical properties of ultrasound lights, hardware limitation, patient physiology and operator errors. ${ }^{9}$

A full bladder is recommended for standard TAUSG , therefore an acoustic window is created for the pelvic organs. The filled bladder pushes the intestines out of the pelvis and the pelvic organs are displaced 5-10 $\mathrm{cm}$ away from the abdominal wall. ${ }^{10}$ Acoustic energy decreases uniformly in deep tissues. ${ }^{9}$ The fact that the uterus is a deeply located organ and adjacent to intestines so the air forms being a difficult barrier to penetrate the ultrasound beam, moreover the $\mathrm{M}$. rectus abdominis muscle and midline

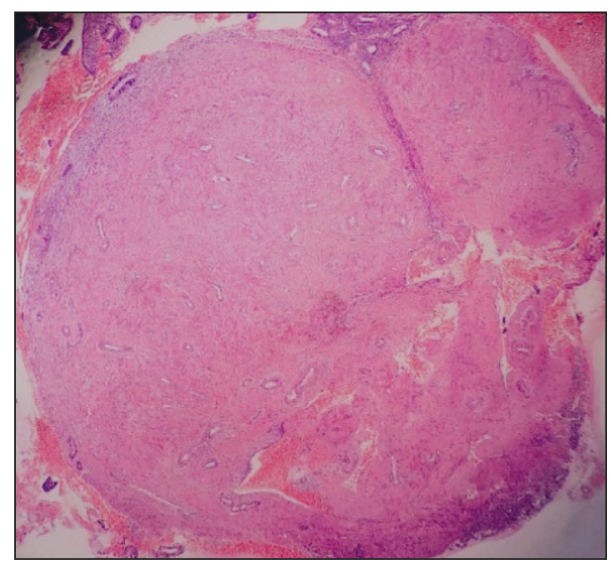

FIGURE 3: Submucosal myoma.

Submucosal myoma specimen consisted of regular shape fascicular smooth muscle bundle separated by vascular connective tissue between endometrial tissue fragments ( $H \& E$ X20). 
adipose tissue induced artefacts prevent the clear visualization of deeply located organs in two-dimensional TAUSG. ${ }^{9}$

Colour Doppler, one of the conventional Doppler techniques, is insufficient to display all Doppler spectrum due to artefacts such as colour confusion, noise, etc. and is mostly used in echocardiography and vascular USG. ${ }^{10,11}$ Power Doppler is more convenient in the evaluation of weak low-flow vessels and ischemic areas due to advantages such as the lack of colour confusion, high sensitivity in flow detection, homogeneous background colour etc. however it is mostly used in the evaluation of superficial organs such as thyroid, testicles, etc. as it is very sensitive to motion artefacts. ${ }^{10,11}$ SMI Doppler is a technique that eliminates the artefact that develops due to tissue movement, therefore, it provides superiority over conventional Doppler methods by displaying low velocity blood flows in vessels with small diameters, so in the literature there are some studies related to strong diagnostic value of SMI-Doppler technique in the vascular imaging of the organ lesions such as; liver, skeletal muscle, thyroid, breast, placenta etc. ${ }^{3,12}$

EPs are the benign focal enlargement of endometrial glands, stroma and vascular structures. ${ }^{13,14}$ They are typically benign lesions, however they can show hyperplasia or malignant transformation at a rate of $0.1 \% .^{14,15}$ They are responsible for $30 \%$ of post-menopausal bleedings and multiple polyps are seen in the post-menopausal period at a rate of $26 \% .{ }^{16,17}$ In polyp histopathology, endometrial glands characteristically arranged parallel to the surface epithelium, glands are often dilated, spaced and differently shaped, and extracellular connective tissue includes thin-walled stromal blood vessels. ${ }^{18,19}$.

SMM is a type of myoma that results in bleeding in the postmenopausal period. ${ }^{20}$ In small magnifications in microscopic view, they are spindle-shaped, smooth muscle cells forming right angles with each other that are arranged in bundles. These muscle bundles stretch and form vortex-shaped long distances. The cytoplasm of these spindle-shaped and long cells is resmall pink fibres in HaematoxylinEosin staining. ${ }^{21}$
The incidence of EP in case series with postmenopausal bleeding and endometrial thickness of 5 $\mathrm{mm}$ and above is reported to be $30.1 \% / 35.3 \%$ and SMM 6\%/2.9\% respectively in the literature. ${ }^{22,23}$ Due to the limited number of cases in our study, a relatively high rate of SMM was found compared to the literature.

SMM and EPs can be of different echogenicities and sizes. Hypo-iso-hyperechogenic, heterogeneous, mixed echogenic appearance in SMM cases and hyperechogenic appearance in EP have been reported in the literature. ${ }^{24-28}$ Similar to the literature, a hyperechogenic morphological appearance has been detected in SMM and EP in our study.

Doppler vascular pattern is important in the evaluation of endometrial morphology. Cogendez et al., detected $80 \%$ single veins, $7.5 \%$ multiple veins, and $12.5 \%$ avascular appearance in EP cases in their study. ${ }^{27}$ Alcázar et al., found that single vessel pattern was compatible with EP in post-menopausal patients. ${ }^{29}$ In several studies in the literature, the sensitivity and positive predictive value (PPD) of single vessel pattern for EP has been reported to be as 80 to $100 \%$ and 81.3 to $92.9 \%$, respectively. ${ }^{27,30}$ Kabil Kucur et al., found sensitivity to be $66.7 \%$, specificity to be $98.2 \%$, PPD to be $96.3 \%$ and negative predictive value (NPD) to be $81.4 \%$ in single vessel patterns in EP. ${ }^{1}$ In our study, a single vessel pattern has been observed in only 2 EP cases.

$72.2 \%$ of SMM cases showed circular vessel pattern while $27.8 \%$ showed multiple vessels in the literature. ${ }^{27}$. Cil et al., reported that the circular or semi-circular image was more demonstrative in SMM compared to multiple vessel patterns. $.^{30} \mathrm{Co}-$ gendez et al., found the sensitivity and PPD of the circular vascular pattern for SMM to be $72 \%$ and $100 \%$ while Cil et al., found these values to be $70.6 \%$ and $100 \%$, respectively. ${ }^{27,30}$ The sensitivity, specificity, PPD and NPD of circular pattern was found to be $80 \%, 100 \%, 100 \%$ and $97.7 \%$, respectively, in the SMM cases, in the literature. ${ }^{1}$ The circular vascular pattern that was specific for SMM could not be detected in our study. Failure to detect vascularity in these cases can be explained by the smallness of the lesions. In a study evaluating myoma vascularity with 
TAUSG-SMI Doppler, it was demonstrated by histopathological correlation that vascularity was more clearly evaluated in large-sized myomas. ${ }^{2}$

\section{CONCLUSION}

In conclusion, we found that TAUSG- SMI Doppler may not be enough for vascular imaging of EP and SMM in postmenopausal overweight women. Transabdominal route, excessive BMI and deeply located organ of uterus may be the factors of this result.

\section{Source of Finance}

During this study, no financial or spiritual support was received neither from any pharmaceutical company that has a direct connection with the research subject, nor from a company that pro- vides or produces medical instruments and materials which may negatively affect the evaluation process of this study.

\section{Conflict of Interest}

No conflicts of interest between the authors and / or family members of the scientific and medical committee members or members of the potential conflicts of interest, counseling, expertise, working conditions, share holding and similar situations in any firm.

\section{Authorship Contributions}

Idea/Concept: Irem Şenyuva, Senem Şentürk; Design: Irem Şenyuva, Senem Şentürk; Control/Supervision: Irem Şenyuva, Senem Şentürk; Data Collection and/or Processing: Irem Şenyuva, Şirin Küçük, Senem Şentürk, Çiğdem Öztürk Turan, Gökçe Ylldırım; Analysis and/or Interpretation: Irem Şenyuva, Senem Şentürk; Literature Review: Irem Şenyuva; Writing the Article: Irem Şenyuva; Critical Review: Senem Şentürk.

\section{REFERENCES}

1. Kabil Kucur S, Temizkan O, Atis A, Gozukara I, Uludag EU, Agar S, et al. Role of endometrial power Doppler ultrasound using the international endometrial tumor analysis group classification in predicting intrauterine pathology. Arch Gynecol Obstet. 2013;288(3):64954. [Crossref] [PubMed]

2. Şenyuva İ, Küçük Ş, Turan Ç, Yüksel G, Şentürk S, Çam C, et al. Uterin fibroidlerin vaskülarizasyonu: SMI (Superb Microvascular Imaging) Doppler ultrasonografi bulgularının histopatolojik korelasyonu. Perinatoloji Dergisi. 2018;26(Suppl):16-9.

3. Hasegawa J, Suzuki N. SMl for imaging of placental infarction. Placenta. 2016;47:96-8. [Crossref] [PubMed]

4. Leone FPG, Timmerman D, Bourne T, Valentin L, Epstein E, Goldstein SR, et al. Terms, definitions and measurements to describe the sonographic features of the endometrium and intrauterine lesions: a consensus opinion from the International Endometrial Tumor Analysis (IETA) group. Ultrasound Obstet Gynecol. 2010;35(1):10312. [Crossref] [PubMed]

5. Kupesic S, Kurjak A, Hajder E. Ultrasonic assessment of the postmenopausal uterus. Maturitas. 2002;25;41(4):255-67. [Crossref] [PubMed]

6. Dowdy SC, Mariani A, Lurain JR. uterus Kanseri. Berek JS. Jinekoloji. 1. Baskı. ErkA, Demirtürk $F$, çeviri editörleri. İstanbul: Nobel Tıp Kitabevi; 2017. p.1250-303

7. Türkiye Endokrinoloji ve Metabolizma
Derneği. Obezite Tanı ve Tedavi Kılavuzu. 8. Baskı. Ankara: BAYT; 2019. p.112. [Crossref]

8. Tartaroğlu C, Polat A, Kargı A, Şengiz S, Çamdeviren H, Küpelioğlu A, et al. [Association of macrophages, eosinophil leukocytes and NK cells with angiogenesis and depth of invasion in colorectal carcinomas]. Turkish Journal of Pathology. 2005;21(3-4):49-53.

9. Prabhu SJ, Kanal K, Bhargava P, Vaidya S, Dighe MK. Ultrasound artifacts: classification, applied physics with illustrations, and imaging appearances. Ultrasound Q. 2014;30(2):14557. [Crossref] [PubMed]

10. Rumack CM, Wilson SR, Charboneau JW. Diagnostic Ultrasound. 2nd ed. St. Louis: Mosby; 1998. p.1860.

11. Hamper UM, DeJong MR, Caskey $\mathrm{Cl}$, Sheth S. Power Doppler imaging: clinical experience and correlation with color Doppler US and other ýmaging modalities. Radiographics. 1997;17(2):499-513. [Crossref] [PubMed]

12. Jiang ZZ, Huang YH, Shen HL, Liu XT. Clinical applications of superb microvascular imaging in the liver, breast, thyroid, skeletal muscle, and carotid plaques. J Ultrasound Med. 2019;38(11):2811-20. [Crossref] [PubMed]

13. Kamaya A, Yu PC, Lloyd CR, Chen BH, Desser TS, Maturen KE. Sonographic evaluation for endometrial polyps: the interrupted mucosa sign. J Ultrasound Med. 2016;35(11):2381-7. [Crossref] [PubMed]

14. Nijkang NP, Anderson L, Markham R, Manconi F. Endometrial polyps: pathogenesis, seque- lae and treatment. SAGE Open Med. 2019;7:2050312119848247. [Crossref] [PubMed] [PMC]

15. Giordano G, Gnetti L, Merisio C, Melpignano M. Postmenopausal status, hypertension and obesity as risk factors for malignant transformation in endometrial polyps. Maturitas. 2007;20;56(2):190-7. [Crossref] [PubMed]

16. Cohen MA, Sauer MV, Keltz M, Lindheim SR Utilizing routine sonohysterography to detect intrauterine pathology before initiating hormone replacement therapy. Menopause. 1999;6(1):68-70. [Crossref] [PubMed]

17. Reslová T, Tosner J, Resl M, Kugler R, Vávrová I. Endometrial polyps. A clinical study of 245 cases. Arch Gynecol Obstet. 1999;262(3-4):133-9. [Crossref] [PubMed]

18. Nogueira AA, Dos Reis FJC, Silva JCRE, Poli Netto OB, de Freitas Barbosa H. Endometrial polyps: a review. J Gynecol Surg. 2007;23(3):111-6. [Crossref]

19. Lieng M, Qvigstad E, Dahl GF, Istre O. Flow differences between endometrial polyps and cancer: a prospective study using intravenous contrast-enhanced transvaginal color flow Doppler and three-dimensional power Doppler ultrasound. Ultrasound Obstet Gynecol. 2008;32(7):935-40. [Crossref] [PubMed]

20. Lasmar RB, Dias R, Barrozo PRM, Oliveira MAP, Coutinho EDSF, da Rosa DB. Prevalence of hysteroscopic findings and histologic diagnoses in patients with abnormal uterine bleeding. Fertil Steril. 2008;89(6):1803-7. [Crossref] [PubMed] 
21. Benda JA. Pathology of smooth muscle tumors of the uterine corpus. Clin Obstet Gynecol. $2001 ; 44(2): 350-63$ [Crossref] [PubMed]

22. Elfayomy AK, Habib FA, Elkablawy MA. Role of hysteroscopy in the detection of endometrial pathologies in women presenting with postmenopausal bleeding and thickened endometrium. Arch Gynecol Obstet. 2012;285(3):839-43. [Crossref] [PubMed]

23. Erdem B, ŞIK BA, Tekin B, Özdemir Y, Salman $S$. [Analysis of the reasons for postmenopausal bleeding that originated from the uterus]. JAREM. 2016;6:78-83. [Crossref]

24. Jorizzo JR, Riccio GJ, Chen MY, Carr JJ. Sonohysterography: the next step in the evaluation of the abnormal endometrium. Radiographics. 1999;19:117-30. [Crossref]
[PubMed]

25. Laifer-Narin SL, Ragavendra N, Lu DS, Sayre J, Perrella RR, Grant EG, et al. Transvaginal saline hysterosonography: characteristics distinguishing malignant and various benign conditions. Am J Roentgenol. 1999;172(6): 1513-20. [Crossref] [PubMed]

26. Bhaduri M, Tomlinson G, Glanc P. Likelihood ratio of sonohysterographic findings for discriminating endometrial polyps from submucosal fibroids. J Ultrasound Med. 2014;33(1): 149-54. [Crossref] [PubMed]

27. Cogendez E, Eken MK, Bakal N, Gun I, Kaygusuz El, Karateke A, et al. The role of transvaginal power Doppler ultrasound in the differential diagnosis of benign intrauterine focal lesions. J Med Ultrason (2001). 2015;42(4):533-40. [Crossref] [PubMed]
28. Davis PC, O'Neill MJ, Yoder IC, Lee SI, Mueller PR. Sonohysterographic ?ndings of endometrial and subendometrial conditions. Radiographics. 2002;22(4):803-16. [Crossref] [PubMed]

29. Alcázar JL, Castillo G, Mínguez JA, Galán MJ. Endometrial blood ?ow mapping using transvaginal power Doppler sonography in women with postmenopausal bleeding and thickened endometrium. Ultrasound Obstet Gynecol. 2003;21(6):583-8. [Crossref] [PubMed]

30. Cil AP, Tulunay G, Kose MF, Haberal A. Power Doppler properties of endometrial polyps and submucosal fibroids: a preliminary observational study in women with known intracavitary lesions. Ultrasound Obstet Gynecol. 2010;35(2):233-7. [Crossref] [PubMed] 